\title{
Undermining Australian parks
}

SIR-Why are the Northern Territory government, mining industry and certain conservationists so strongly opposing the application of the federal government of Australia for the World Heritage listing of Stage 1 of Kakadu National Park to be extended to Stage 2? The reasons are complex. In his article on "Politics and wildlife in Australia" (see Nature 325, 112; 1987), Kenneth Mellanby claimed that Stage 2 of Kakadu "must be the most boring national park in the world" and that it is "substandard" for consideration as a World Heritage site. He and the Australian media conservationist Harry Butler have likened it to a "clapped-out Holden" while members of the Northern Territory government and NT News frequently like to refer to it as "clapped-out buffalo country"

In support of this claim, the Northern Territory government commissioned a video film, in which Harry Butler and Kenneth Mellanby deprecated Kakadu Stage 2. This film depicted a biological wilderness where large herds of feral buffalo were claimed to be responsible for severe environmental degradation. Signs of over-grazing, trampling, wallows and buffalo swim channels were all shown. Certainly buffalo can cause considerable environmental damage. Swim channels in the wetlands may have been one cause of saltwater intrusions into the floodplains, and overgrazing by buffalo has resulted in substantial changes in the vegetation and some erosion in the past. The vegetation has, however, shown a remarkable recovery to its former status since the Australian National Parks and Wildlife Service instigated an intense control programme of the feral buffalo.

The recovery of the vegetation has been rapid in both the woodlands and wetlands. Scientists of CSIRO's Tropical Ecology Research Centre at Darwin have been monitoring these changes. Comparison of a fenced-off area containing buffalo with others vividly illustrates the dramatic changes that have occurred both in the physical structure and species composition of the vegetation since the removal of the buffalo. Yet it was in this maintained high density area of buffalo that Mellanby and Butler did their filming. So misleading was the video that the Darwin group countered this picture of Stage 2 based on their own studies. Why do the two sides differ? Inevitably the judgement of landscapes and biotas is to a certain extent subjective, but, as Paul Adam remarks (Nature 325, $570 ; 1987)$, to describe Stage 2 of Kakadu as "the most boring national park in the world" is a greater reflection on the writer than on the area. Nevertheless the views of the mining industry and the Northern Territory government coincide with those of their well-paid ecological consultants.
What is really at stake here is not the World Heritage value of Kakadu Stage 2 but the control of the park and the mining of uranium. Anything that is going to make mining more difficult is clearly against the interests of the mining companies and can be expected to be opposed by them. There is already one uranium mine (Ranger) that is technically not within the confines of the park but which is entirely surrounded by it. Most of the other known mineral resources (and these are considerable) are in similar positions: excised from the park but entirely surrounded by it.

In the Australian National Parks and Wildlife Service Report to the Senate Standing Committee on National Resources, it was estimated that only 3 per cent of the total mineral resources in the area fell within Stages 1 and 2 of Kakadu National Park or the proposed Stage 3. Nevertheless, decisions to mine within these areas cannot fail to be affected by the conservation value of the surrounding land. Although technically outside the park, they cannot be seen as separate from it. Ranger uranium mine is, for example, now applying to release water into the park when previously it had agreed not to do so.

The exploitation of the Jabiluka mine lease worth an estimated A $\$ 19,000$ million could also pose serious environmental problems as it occurs within an area that is seasonally inundated. For the present, the Australian Prime Minister, Bob Hawke, has stated that he wants to see no further mining within the Kakadu area, but a change in government or economic circumstances could well lead to a change in this decision. The exploitation of these mineral resources will then clearly be a lot easier if they are not surrounded by a World Heritage Conservation site.

Finally, what can be said of the views of the aborigines, the traditional owners of much of the land within Stages 1 and 2 of Kakadu? Mellanby gives the impression that the park authorities are out of touch with their views. My experience was entirely to the contrary. There is considerable understanding and liaison: moreover, 40 per cent of the Australian National Parks and Wildlife Service staff are aboriginals. They receive royalty payments from the uranium mining at Ranger but they, like other Australians, are divided on whether further exploitation should take place. The considerable pressures that have been put on them to accept mining have, however, been eloquently expressed by their leader, Bill Neidjie, in a recent Australian television report.

The mix of ecological, economic, social and political factors represented in the Kakadu debate are complex. The conser- vation and mineral wealth of the area are both extremely large. Legal action in the federal courts has led to a postponement over any decision on the World Heritage listing of Kakadu Stage 2. But whatever the decision, the battle over mining is likely to continue: the financial rewards are too great for it to be otherwise.

ANDREW WATKINSON

School of Biological Sciences,

University of East Anglia,

Norwich NR4 7TJ, UK

\section{Food for thought}

SIR-Some archaeologists suffer from an unnecessary anxiety that may affect their perception of the evolution of early man. On the one hand, it has recently become apparent that meat-eating is a health hazard for our species. On the other, our immediate forebears, the Homo sapiens evolving in periglacial environments, must have been substantially carnivorous Surely evolution should have fitted modern man to a diet at least as rich in animal material as his present one?

A popular explanation is that lack of exercise accounts for the condition of modern man. But exercise alone does not seem to be sufficient to protect us from the cardiovascular ailments consequent on meat-eating.

An explanation that appears to have escaped attention is that modern prey species may be to blame. Wild deer, ibex and so on yield exceedingly lean meat, low in fat, quite unlike the meat consumed in modern diets. Modern animals are deliberately denied the benefits of aerobic exercise.

Our health problem, it would seem, can be overcome by the straightforward expedient of avoiding being placed higher in the food chain than a lazy animal.

1267 Four Mile Canyon Drive,

GEOFFREY KING

Boulder, Colorado 80302, USA

Allan Lindh

4185 Page Mill Road,

Los Altos Hills,

California 94022, USA

\section{Aluminium alarm}

SIR-I read with interest of the concern of Coriat and Gillard (Nature 321, 570; 1986) about aluminium in tea, and the report of Tennakone and Wickeramanayake (Nature 325, 201; 1987) on aluminium from cooking utensils.

Why are, they concerned about aluminium from these sources compared to the substantially larger amounts added directly to many foods, such as alum in baking powder and pickles?

G. M. WILD

Eli Lilly and Company,

Lilly Corporate Center,

Indianapolis, Indiana 46285, USA 